\title{
The SPIRIT airborne instrument: a three-channel infrared absorption spectrometer with quantum cascade lasers for in situ atmospheric trace-gas measurements
}

\author{
Valéry Catoire $^{1}\left(\mathbb{D} \cdot\right.$ Claude Robert $^{1} \cdot$ Michel Chartier $^{1} \cdot$ Patrick Jacquet $^{1}$. \\ Christophe Guimbaud $^{1}$ - Gisèle Krysztofiak ${ }^{1}$
}

Received: 16 April 2017 / Accepted: 28 August 2017 / Published online: 5 September 2017

(c) The Author(s) 2017. This article is an open access publication

\begin{abstract}
An infrared absorption spectrometer called SPIRIT (SPectromètre Infra-Rouge In situ Toute altitude) has been developed for airborne measurements of trace gases in the troposphere. At least three different trace gases can be measured simultaneously every $1.6 \mathrm{~s}$ using the coupling of a single Robert multipass optical cell with three Quantum Cascade Lasers (QCLs), easily interchangeable to select species depending on the scientific objectives. Absorptions of the mid-infrared radiations by the species in the cell at reduced pressure $(<40 \mathrm{hPa})$, with path lengths adjustable up to $167.78 \mathrm{~m}$, are quantified using an $\mathrm{HgCdTe}$ photodetector cooled by Stirling cycle. The performances of the instrument are assessed: a linearity with a coefficient of determination $R^{2}>0.979$ for the instrument response is found for CO, $\mathrm{CH}_{4}$, and $\mathrm{NO}_{2}$ volume mixing ratios under typical tropospheric conditions. In-flight comparisons with calibrated gas mixtures allow to show no instrumental drift correlated with atmospheric pressure and temperature changes (when vertical profiling) and to estimate the overall uncertainties in the measurements of $\mathrm{CO}, \mathrm{CH}_{4}$, and $\mathrm{NO}_{2}$ to be $0.9,22$, and $0.5 \mathrm{ppbv}$, respectively. In-flight precision $(1 \sigma)$ for these species at $1.6 \mathrm{~s}$ sampling is $0.3,5$, and $0.3 \mathrm{ppbv}$, respectively.
\end{abstract}

\section{Introduction}

In recent years, infrared laser absorption spectroscopy has been successful for atmospheric measurements of small

Valéry Catoire

valery.catoire@cnrs-orleans.fr

1 Laboratoire de Physique et Chimie de l'Environnement et de l'Espace (LPC2E), Université Orléans-CNRS, 3A Avenue de la Recherche Scientifique, 45071 Orléans Cedex 2, France trace gases, enabling fast online and precise measurements with compact instrumentation. This technique has been implemented in aircraft $[1,2]$, and is now more and more widespread. Most recently built airborne instruments comprise several variants, i.e., non-resonant cavities using tunable diode lasers (see, e.g., [3-6] and references therein), quantum cascade lasers (QCL; see, e.g., [7, 8] and references therein), or difference frequency generation lasers [9], and resonant cavities for cavity ring-down spectroscopy (CRDS) [10-12], off-axis integrated cavity output spectroscopy (OAICOS) [13-15], or optical-feedback cavity enhanced absorption spectroscopy (OF-CEAS) [16]. Using lasers allows for narrow linewidths, leading to selectivity of trace gases and very low limits of detection. Using QCLs, which emit in the Mid-Infrared (MIR) domain, leads to stronger absorptions than in the near infrared due to the molecular fundamental transitions taking place and, therefore, again to higher sensitivity. Among other advantages, QCLs possess high optical output power, which is useful for long optical path operation. First used in pulsed mode, QCLs begin to be operated in continuous-wave $(\mathrm{CW})$ mode, resulting in negligible linewidths [17] with respect to the molecular absorption line at the operation pressure. As a result, this leads to measurements of intrinsically higher accuracy and sensitivity.

For more than 20 years, our group, in collaboration with the French space agency CNES (Centre National d'Etudes Spatiales), has developed a series of balloon-borne instruments using optical spectroscopy techniques with remote (stars, moon) or in situ (embarked lasers) light sources for the detection of stratospheric species [18-20]. In the present paper, we present a newly built airborne instrument called SPIRIT (SPectromètre Infra-Rouge In situ Toute altitude). SPIRIT performs ultra-high-resolution $\left(<0.001 \mathrm{~cm}^{-1}\right)$ infrared absorption spectroscopy thanks to the use of three MIR CW-QCLs (with FWHM of emission lines lower than 
$4 \times 10^{-4} \mathrm{~cm}^{-1}$ ) coupled with a single non-resonant cavity, a Robert cell in the present case [21]. This is a multiplereflection cell patented by our group, combining the design of the Herriott and White cells, allowing for longer optical paths (for the same size). This arrangement leads to a unique compact and versatile spectrometer for quantifying in situ abundances of at least three atmospheric trace gases, which can be selected using suitable QCLs, depending on the objectives of each project. We first targeted $\mathrm{CO}, \mathrm{NO}_{2}$, and $\mathrm{CH}_{4}$ for their potential to answer chemical pollution and air masses transport issues in various projects extending from the lower to the upper troposphere.

After this introduction, we describe in Sect. 2, the optomechanical setup, the control-acquisition electronics of the instrument and the data retrieval process. The performances of the measurements obtained in the laboratory and in-flight are given in Sect. 3. The possible applications of SPIRIT measurements are rather for local or regional pollution event studies. Therefore, species concentrations are measured within the range of background to enhancement levels representative of pollution events. Using spectroscopic data from HITRAN database [22] is sufficient to attain the required accuracy (a few \% according to this database), since these data contain all the information to model the line shapes and intensities as a function of experimental conditions (temperature, pressure, and gas nature). In its present configuration, SPIRIT is not designed for long-term greenhouse gas monitoring to be reported onto known global calibration scale (e.g., WMO/GAW network). Indeed, this monitoring can be conducted by commercially available instruments (e.g., Picarro Inc., Los Gatos Research Inc., Aerodyne Research Inc.) and needs regular in-flight calibrations $[7,8,10,13]$ at the expense of valuable ambient acquisition such as sudden unexpected increases in abundances of species. Moreover, in-flight calibrations are possible essentially for stable greenhouse gases and $\mathrm{CO}$ using embarked cylinders, but more difficult to handle with reactive or sticky species. Besides these commercial spectrometers, developing and implementing home-made instruments such as the one presented here are valuable. This leads to a complete independent mastering of the process for data acquisition and molecular concentration retrievals, and enables immediate diagnosis and swift repair in case of failure during field campaigns.

\section{Description of the instrument}

\subsection{Instrumental design}

As a multichannel tunable laser spectrometer, SPIRIT consists of laser sources, an optical cell, where the trace gas is continuously sampled, photodetectors, and an electronic system controlling laser functioning and data acquisition. The instrumental principle for ground measurements with one single channel and the process to retrieve molecular concentrations of the trace gases have been described previously [23]. The present paper only deals with the details related to the three-channel airborne version. Figure 1 shows 3D drawings of the SPIRIT instrument integrated in the aircraft rack, using a computer-aided design (CAD). The instrument weighs $102 \mathrm{~kg}$, its dimensions are $95.8 \times 55.9 \times 65.4 \mathrm{~cm}^{3}$, and its power consumption is less than $1.2 \mathrm{~kW}$.

A schematic representation of the operation principle is given in Fig. 2. SPIRIT operates with three ContinuousWave Distributed-Feedback Room-Temperature QCLs (CWDFB-RT-QCLs from Alpes Lasers SA; see characteristics given hereafter, as shown in Table 1), corresponding to the three measurement channels, coupled to one optical cell and two detectors only-one for the measurement channels and the other one for the reference channels. The home-made main electronic module receives commands from a laptop computer via an RS-232 link and drives the current and

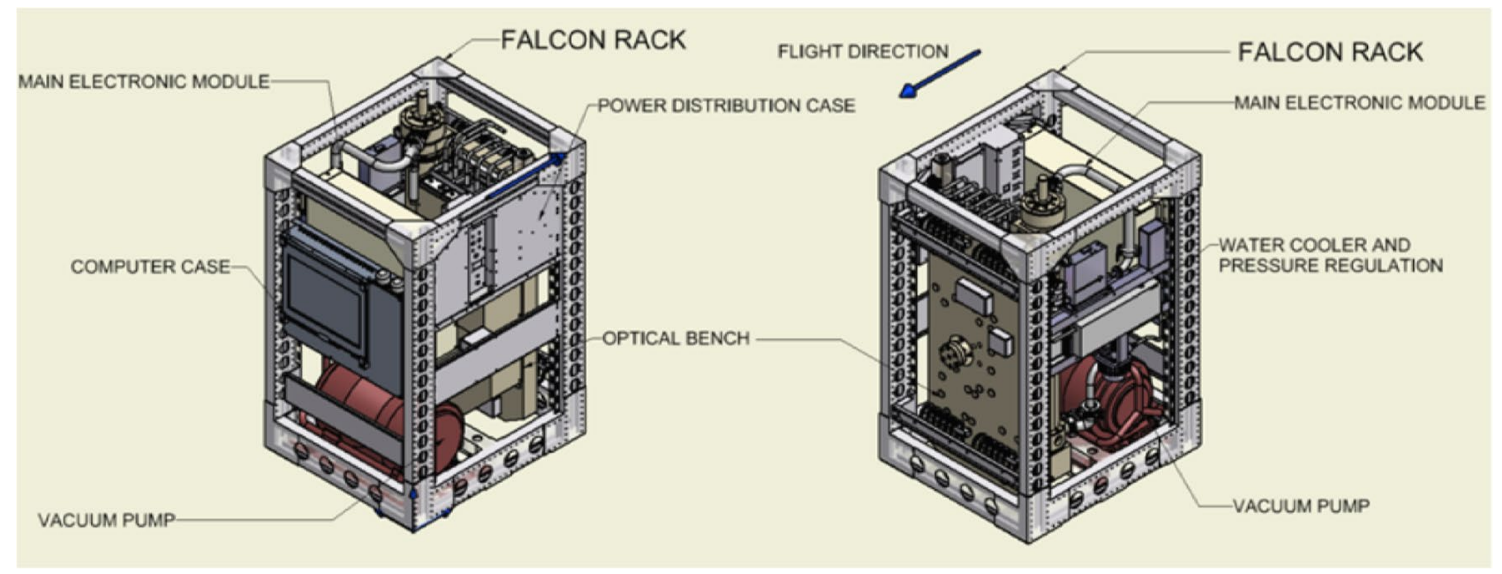

Fig. 1 3D drawings of the instrument integrated in the Falcon aircraft rack 


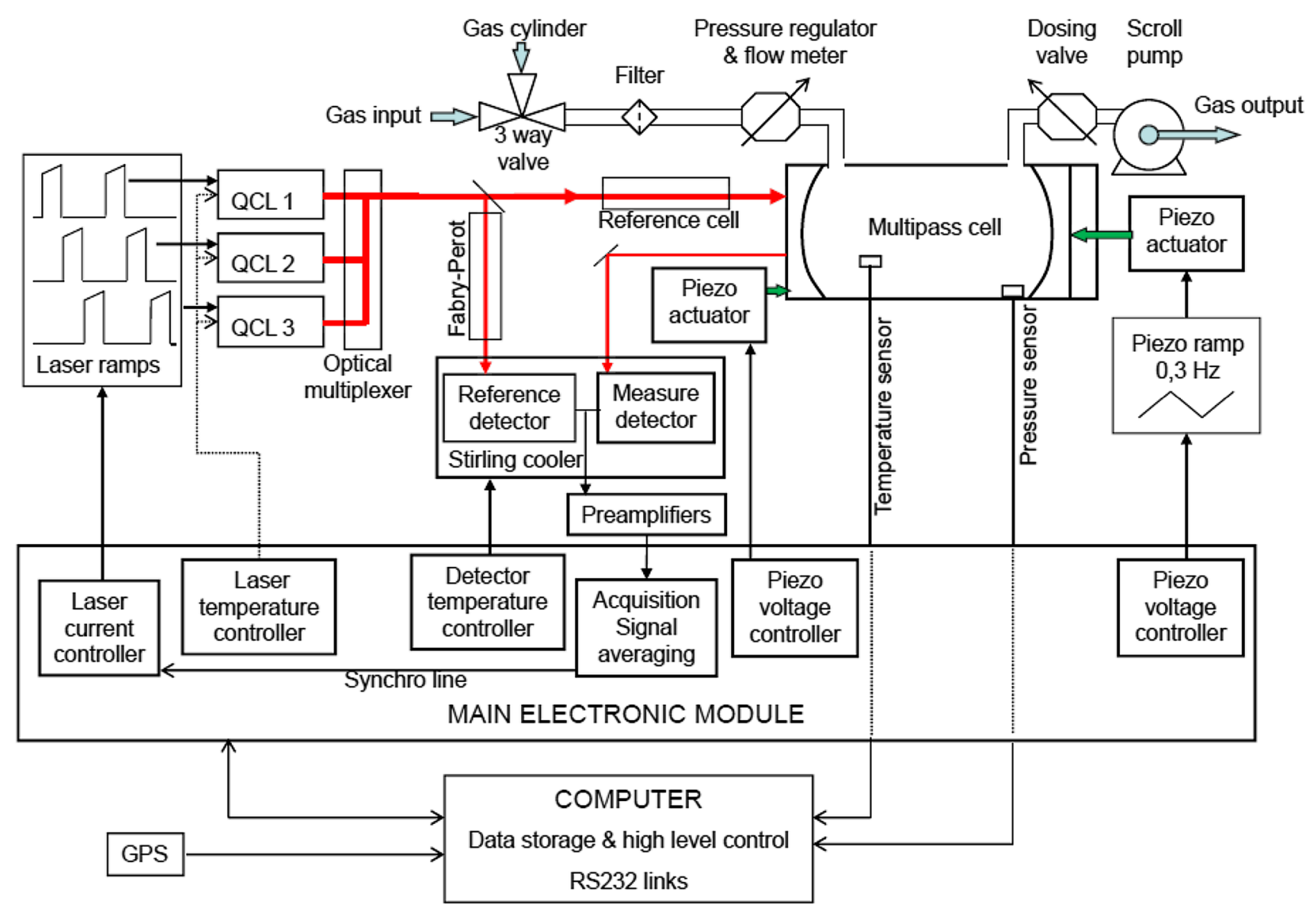

Fig. 2 Schematic principle of the instrument

Table 1 Spectral micro-windows and emission conditions of the QCLs

\begin{tabular}{llll}
\hline Molecule & Spectral domain $\left(\mathrm{cm}^{-1}\right)$ & $\begin{array}{l}\text { Cur- } \\
\text { rent }+ \text { ramp } \\
(\mathrm{mA})\end{array}$ & $T\left({ }^{\circ} \mathrm{C}\right)$ of the QCL \\
\hline $\mathrm{CO}$ & $2179.6-2179.9$ & $600+13$ & -12.5 \\
$\mathrm{NO}_{2}$ & $1630.15-1630.55$ & $410+20$ & -15.5 \\
$\mathrm{CH}_{4}, \mathrm{~N}_{2} \mathrm{O}$ & $1277.1-1277.6$ & $460+30$ & +17.0 \\
\hline
\end{tabular}

temperature controllers for each of the three QCLs. Each temperature controller consists of a Peltier thermoelectric module that maintains individually each laser chip at a constant temperature, with a typical precision of $1 \mathrm{mK}$, allowing for laser single-mode emission at a precise wavenumber. A water-glycol circuit regulated at a constant temperature $\left(13{ }^{\circ} \mathrm{C}\right)$ allows for removing excess heat from each Peltier cooler and the Stirling detector cooler, using a liquid pump (Ecocirc Laing) and a liquid-air thermal exchanger (LA115 Laird Technologies). The three QCLs are sequentially switched on/off and synchronized by the data acquisition system. For each QCL, the current controller applies a saw-tooth ramp of several $\mathrm{mA}$ during $4.1 \mathrm{~ms}$ to sweep a spectral micro-window of interest for the species to quantify. This ramp is repeated 110 times for measurement spectra followed by eight times for reference spectra. The whole sequence containing measurements for the three channels are thus recorded within $1.6 \mathrm{~s}$, including averaging and transfer of these data to the laptop computer. All along this paper, volume mixing ratios (vmr) are used as relevant quantities, defined as mole fractions relative to the air (usually expressed in part per billion in volume-ppbv), which is a common practice in the atmospheric community. Roughly calculated preliminary vmr (only based on absorption depths of the line centers corresponding to known vmr measured in the laboratory) are inferred and displayed online to be able to modify live the flight trajectory. In addition, the data are stored on the computer for post-processing, leading to retrievals of the trace-gas vmr, as detailed in Sect. (2.2).

The optical bench is presented in Fig. 3. The main mechanical component is a 5-cm-thick aluminum honeycomb composite panel vertically oriented. It is inserted in the aircraft rack with vibration-shock absorbers suitably dimensioned to the airplane acceleration requirements. In these 
Fig. 3 CAD schematics of the optical bench; the red rays symbolize the laser beams

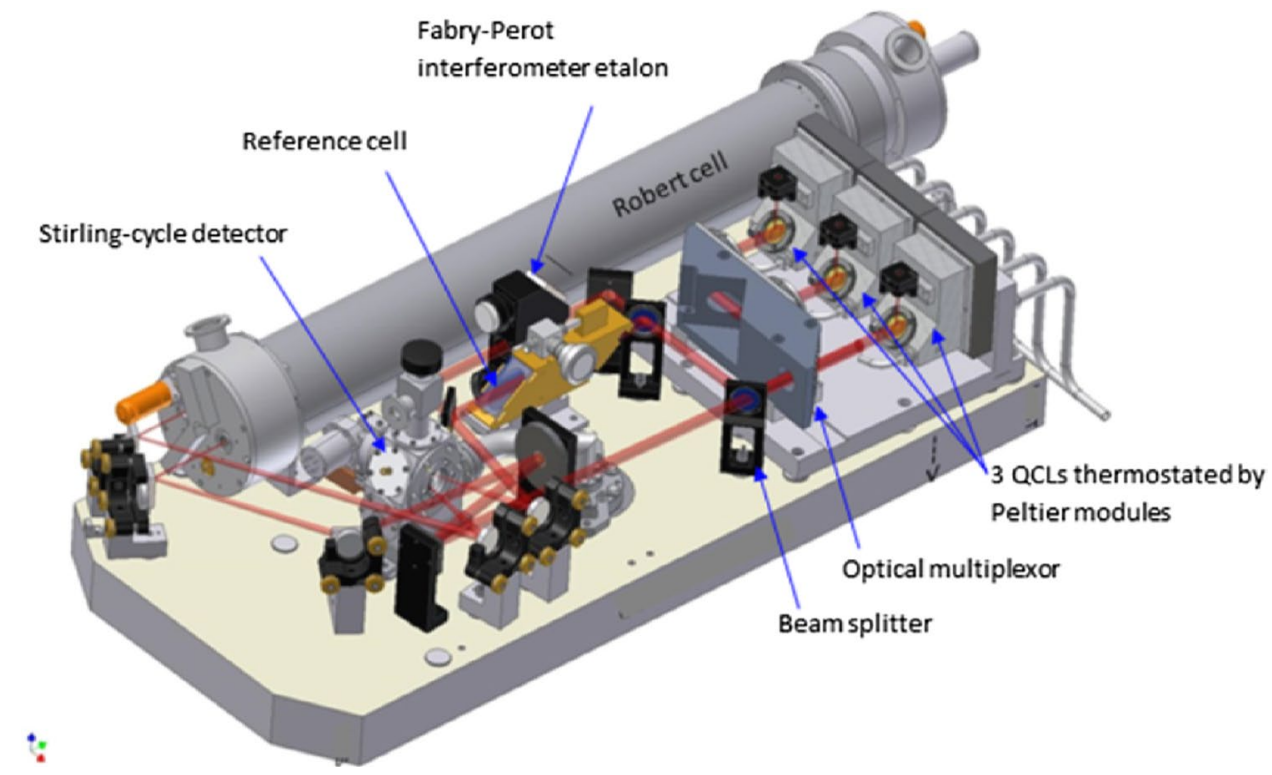

conditions, the maximum bench amplitude of displacement is less than $3 \mathrm{~cm}$. The optical cell is made of a glass tube (8-cm outside diameter, 3 -mm thick, and 62.5-cm length) in low thermal expansion borosilicate. The two tube ends are bonded in two adapted thermal expansion pieces. The optical cell is rigidly fixed on the upper end to the optical bench, and the lower end is free to glide on a V-shaped mount to avoid constraint due to the different thermal expansions between aluminum and glass. The QCL housings include off-axis parabolic mirrors of 5-mm focal length, mounted on the same thermoelectrically cooled copper mechanical support as the laser itself for optical alignment stability. All three laser beams, symbolized by red rays in Fig. 3, go out from these housings through an anti-reflection $\mathrm{ZnSe}$-coated window. An optical multiplexor allows for the spatial superposition of the three beams which then go out onto a $\mathrm{BaF}_{2}$ beam splitter, dividing them into two parts. A minor part is sent through a home-made Fabry-Pérot interferometer etalon used as reference channel for relative wavenumber calibration, since the current ramp does not lead to a precisely linear wavenumber sweep by the QCLs. This beam is then focused onto a photovoltaic HgCdTe detector (Judson J19D10) by a spherical mirror. The detector is linear enough, so that it does not influence the measurements, because it is biased in voltage (typically $100 \mathrm{mV}$ ). This has been verified by attenuating the incident intensity of the laser beam using different grids to verify that the molecular line absorptions do not depend on the light power. The major part of the beam is directed and focused on the entrance of the multipass optical cell through a $\mathrm{BaF}_{2}$ window. Before entering this cell, the beam can pass through a small reference cell containing known gaseous species added for retrieving the absolute wavenumber scale and checking the spectral tuning. This is the case for $\mathrm{NO}_{2}$ measurements for which a cell (of $3-\mathrm{cm}$ long) with $\mathrm{CH}_{4}(100 \mathrm{hPa}$ at $\sim 120 \mathrm{ppmv}$ ) is used, leading to $\sim 1 \%$ absorption of a doublet centered at $1630.407 \mathrm{~cm}^{-1}$. Indeed, $\mathrm{NO}_{2}$ atmospheric abundance is highly variable, even down to below the detection limit ( 0.3 ppbv, as indicated in Sect. 3.2). The measurement output beam goes through a second $\mathrm{BaF}_{2}$ window and is then collected by a flat mirror and focused onto an analogous detector by a spherical mirror similar to the reference beam. Both detectors are cooled by the same Stirling cycle cooler (RM2 Thalès Cryogénie) mounted in a home-made Dewar in which vacuum is maintained by passive pumping using high porosity-sintered materials (CapaciTorr ${ }^{\circledR}$ D 100 Saes Getters). The detected electrical signals are amplified, first by pre-amplifiers with a fixed gain and second by an automatically adjusted gain in the main electronic module, and digitized by a 16-bit analog-to-digital converter.

The optical cell is detailed in a previous paper [21]. In brief, this cell is composed of three mirrors combining the advantages of the Herriott and White cells, which results in very easy and stable operating conditions and allows for very long optical paths, i.e., from $117.45 \mathrm{~m}$ (181 reflections) to $167.78 \mathrm{~m}$ (259 reflections) in the present experiments, in a compact volume $(2.77 \mathrm{~L}$ for a cylinder of $7.4-\mathrm{cm}$ internal diameter and 64.5-cm length). Mirror alignments are controlled by two high-performance piezoelectric actuators (Newport PZA12) located at each of its ends, shown in Fig. 3 (in orange color), allowing optical alignment at desired path length and also the change in the pass number by tilting the two mirrors relative to each other [21]. A third actuator (not visible in Fig. 3) is used to move slowly $(0.3 \mathrm{~Hz})$ back and forth the stand-alone mirror on a small range. As a result, unavoidable interference fringes between 
laser beams and scattered light from the optical components are efficiently attenuated. The temperature of the sampled gas in the cell, measured by means of a Pt100 resistance probe (precision of $0.01 \mathrm{~K}$ ), is accurate and homogeneous to within $1 \mathrm{~K}$ (when the air conditioning system is operating properly). Its value is needed to fit the molecular lines using spectroscopic parameters and to derive the gas vmr. The temperature homogeneity is made possible by the use of aluminum, a very good thermal conductor as material constituting the optical bench and the jacket of the optical cell. Homogeneity to within $1 \mathrm{~K}$ has been checked by measuring temperature simultaneously at several positions along the optical cell for several hours. The air is sampled through a rear-facing stainless steel inlet of 16-mm inside diameter (i.d.), placed in front of the aircraft on the roof of the cabin to avoid contamination. A 1/2" (12.7 mm) i.d. PFA Teflon tubing (less porous and adsorbing than PTFE) is inserted inside this inlet and connected via a $6 \mathrm{~mm}$ o.d. (Swagelock) stainless steel valve to a pressure regulator (MKS 649) upstream of the cell (Fig. 2). The gas is thermalized along $\sim 3 \mathrm{~m}$ of the tube, according to our calculations based on laws of fluid dynamics. This is confirmed under several various experimental conditions that show no correlation between external air temperature and cell air temperature, even for differences greater than $40{ }^{\circ} \mathrm{C}$ (as will be illustrated in Fig. 9). The air is continuously drawn through the optical cell using a scroll pump (XDS10 Boc Edwards) fixed with vibration absorbers on the rack floor. The pressure is constantly maintained at a reduced level of 30-35 hPa by the pressure regulator, accurately known $( \pm 0.1 \mathrm{hPa})$ using a temperature regulated 0-100 $\mathrm{hPa}$ gauge (DTM Scaime), and the flow is set before the experiments by a manual dosing valve (EVN116 Pfeiffer) located at the cell output, upstream of the pump, as shown in Fig. 2 (labelled flow control). This leads to an effective flow rate of $0.316-0.527 \mathrm{~L} \mathrm{~s}^{-1}$ in the cell at $35 \mathrm{hPa}$ and $25^{\circ} \mathrm{C}$ (corresponding to $0.600-1.000$ standard liter per minute-SLM), measured by the mass flowmeter combined with the pressure regulator. The exit line of the vacuum pump is connected to the exhaust tube on the floor or on the roof of the aircraft cabin.

Once switched on, SPIRIT operates fully automated measurements. To compensate for any dimensional drifts, optical realignment (lasting $1 \mathrm{~min}$ ) can be regularly performed using the two piezoelectric actuators. Its frequency can be chosen, e.g., every $10 \mathrm{~min}$ in the case of the absence of a human operator (a compromise between the loss of atmospheric measurements and the degradation of the measurement quality by the decrease of the signal-to-noise ratio). A GPS system (Garmin GPS18) giving universal time, altitude, latitude, and longitude is implemented, on which the laptop computer is synchronized. This has proven to be very useful for the data interpretation, enabling easy comparison with the data of the aircraft and the other scientific instruments on board. Finally, it should be underlined that the materials and functioning of the SPIRIT instrument fulfil the international regulations concerning aircraft equipment and led to certification for installation in three aircrafts: the DLR Falcon-20 (established by Enviscope $\mathrm{GmbH}$ ) and the CNRS/INSU-Météo France Falcon-20 and ATR-42.

\subsection{Data retrieval}

The laser tunings over the three spectral micro-windows (channels) indicated in Table 1 allow for matching the wavenumber $\tilde{v}_{0}$ of the ro-vibrational lines of the molecule to quantify, i.e., $\mathrm{CO}$ at $2179.772 \mathrm{~cm}^{-1}, \mathrm{CH}_{4}$ at $1277.473 \mathrm{~cm}^{-1}$ and $\mathrm{N}_{2} \mathrm{O}$ at $1277.235 \mathrm{~cm}^{-1}$, and $\mathrm{NO}_{2}$ at $1630.326 \mathrm{~cm}^{-1}$ (with a $\mathrm{CH}_{4}$ doublet centered at $1630.407 \mathrm{~cm}^{-1}$ in the reference cell).

As previously explained in detail [20, 23], the molecular concentrations are obtained by fitting the numerical second derivative with respect to the wavenumber of the measured transmission to that of the theoretical transmission (from the Beer-Lambert law) at each wavenumber $\tilde{v}$ of the spectral micro-window using a linear regression algorithm to minimize the sum of squared residuals. The second derivative method is more advantageous as it does not need the accurate reconstruction of the $100 \%$ transmission baseline (the continuous component of the signal), where the molecules absorb, and it reduces the effect of the optical interference fringes. The spectroscopic parameters are taken from the HITRAN 2012 database [22]. Considering the intermediate range of pressure, where neither the pressure (Lorentzian) nor the Doppler (Gaussian) broadenings are predominant, the line shape is assumed to be a Voigt profile. An example of a direct transmission and its second derivative for a $\mathrm{CO}$ spectrum is shown in Fig. 4. The fitting errors on the retrieval (the minimum residual) are about $1 \%$ at $1 \sigma$ confidence level in this figure and on average for the measurements of each species.

In principle, the absorption measurements may be considered absolute and do not require a calibration if accuracy is expected to be about that of the spectroscopic database. The uncertainties on the spectroscopic parameters [22], essentially the lines strengths and air broadening factors (5\% maximum each), affect the accuracy of the trace-gas concentrations by 5 and $2.5 \%$, respectively, as derived from a sensitivity analysis.

Vmr are derived knowing the total pressure $p$ and the temperature $T$ of the optical cell. These are measured with accuracies of $0.2 \mathrm{hPa}$ and $1 \mathrm{~K}$, leading to 0.3 and $0.4 \%$ accuracies in the inferred vmr, respectively, according to a sensitivity analysis. The dry vmr of the trace gases are then deduced using the water vapor mixing ratios measured by SPIRIT at $1277.270 \mathrm{~cm}^{-1}$ (on the $\mathrm{CH}_{4}-\mathrm{N}_{2} \mathrm{O}$ channel), and the $\mathrm{H}_{2} \mathrm{O}$ vmr agree with measurements reported by the core instrumentation installed on the aircraft within $10 \%$. 


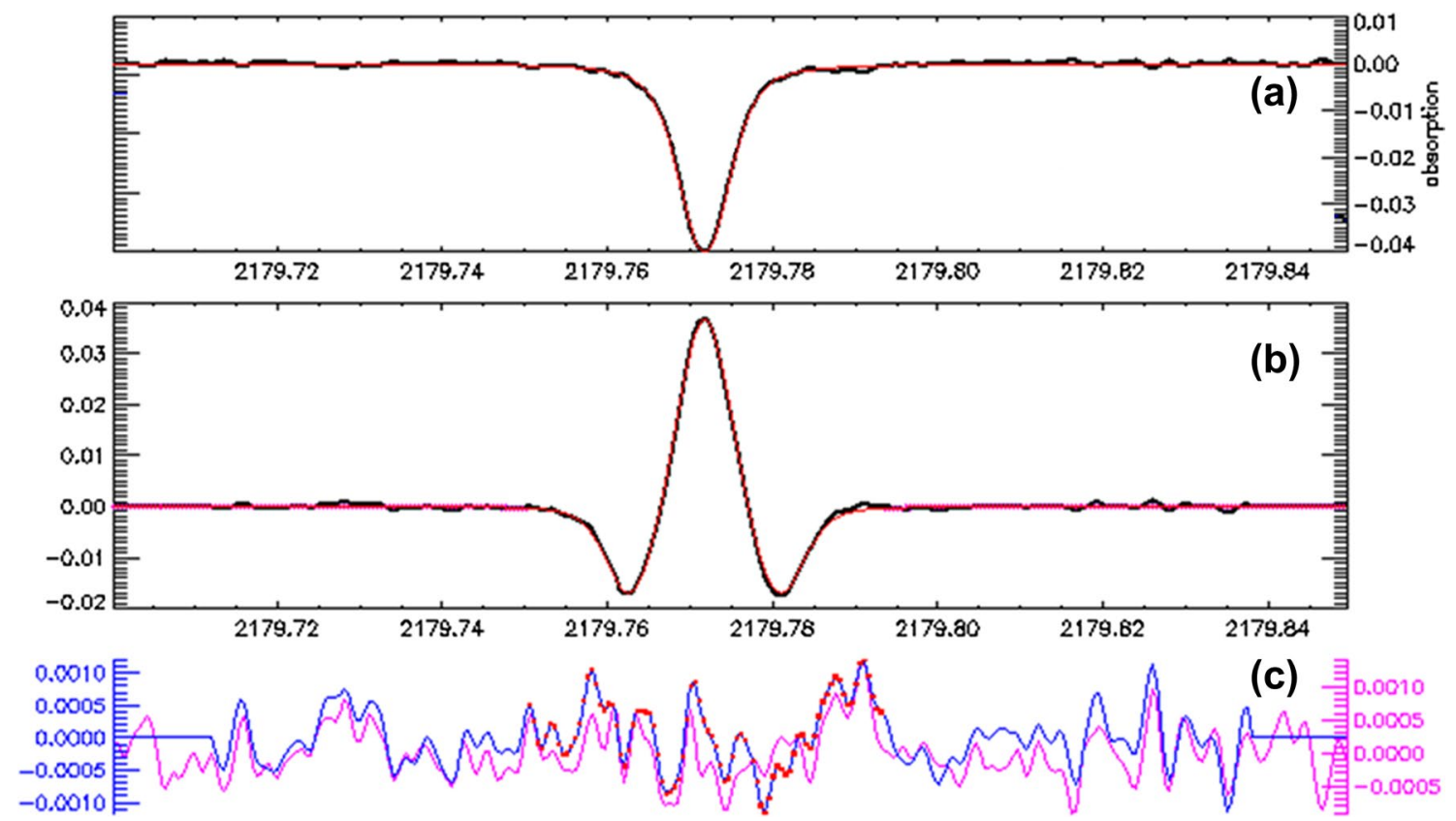

Fig. 4 a Example of experimental (black line) and simulated (red line) transmission spectra for $\mathrm{CO}$ at $31.7^{\circ} \mathrm{C}$ and $32.0 \mathrm{hPa}$, with pathlength of $134.22 \mathrm{~m}$, leading to $\mathrm{CO}$ vmr of $89.1 \pm 0.9$ ppbv. b Experi- mental (black line) and simulated (red line) second derivatives of this transmission signal. c Minimum residuals of the direct transmission (pink line) and of the second derivative (blue line)
Depending on the plane and on the altitude level, this instrumentation is a dew or a frost point temperature hygrometer (CR2 from Buck Research), a lyman-alpha fluorescent spectrometer, or a tunable diode laser absorption spectrometer (WVSS-II from SpectraSensors). This 10\% disagreement represents the accuracy in the $\mathrm{H}_{2} \mathrm{O} v \mathrm{mr}$, and for $\mathrm{H}_{2} \mathrm{O}$ volume mixing ratios of $1 \%$ maximum encountered in the free troposphere, this leads to a maximum contribution of $0.1 \%$ to the uncertainty for the dry mixing ratios. By taking into account all the above potential errors, the overall estimated uncertainties calculated as the square root of the quadratic sum are $5.7 \%$ for all dry volume mixing ratios.

\section{Results: performances of the instrument}

Investigations were carried out to assess SPIRIT instrumental performances. As it is designed to be airborne and is mainly used for that purpose, and because environmental conditions drastically differ in a plane from those that may be encountered in a laboratory, emphasis was placed on describing its performances during real flight operations when it was possible.

\subsection{Laboratory experiments}

Response time has been evaluated by subjecting the instrument to sudden positive and negative variations of carbon monoxide of about 100 ppbv. For six measurements, the mean rise time between 10 and $90 \%$ of the step, $8.6 \pm 0.3 \mathrm{~s}$, was consistent with the fall time, $8.8 \pm 0.3 \mathrm{~s}$, for a standard flow rate set to 0.600 SLM (used for flights in the upper troposphere). These values correspond to the theoretical overall flush time $(8.7 \mathrm{~s})$ of the cell, showing the absence of significant dead volumes that could affect the instrument accuracy. This response time is lowered to $5.2 \mathrm{~s}$ for a 1.000 SLM flow rate when the flight occurs in the lower troposphere. Larger flows are reachable at ground, but are not sustainable at the highest altitudes, where ambient pressure decreases below $250 \mathrm{hPa}$, due to the limited size of the pressure regulator orifice and leads to the impossibility of maintaining stable pressure inside the cell. Similar performances are obtained for $\mathrm{CH}_{4}$ and $\mathrm{N}_{2} \mathrm{O}$. Concerning stickier molecules such as $\mathrm{NO}_{2}$ or $\mathrm{H}_{2} \mathrm{O}$, response time has not been directly evaluated, considering their propensity to adsorb and desorb on surfaces, where they can easily react. One can assume the response time to vary and to somewhat exhibit dependence towards temperature and the chemical passivation state of the cell walls, which itself depends on the concentrations of the gases previously passed through the analyzer and the elapsed time. However, in-flight applications for tracking aircraft contrails in the upper troposphere and oil platform plumes in the boundary layer at 3-year interval have shown that response time for measurement variations of $\mathrm{NO}_{2} \mathrm{vmr}$ was not affected by more than a few seconds by this artefact. 
A leak rate was found to be about $1.1 \times 10^{-3} \mathrm{hPa} \mathrm{L} \mathrm{s}^{-1}$, representing $1.4 \times 10^{-4}-8.1 \times 10^{-5}$ of the sampled gas flow rate. If one considers the worst case, where the ambient trace-gas concentration is greater than that of the sampled air by one order of magnitude (such as might be in the aircraft cabin), the relative error resulting from leaks should not exceed $0.15 \%$.

The linearity of SPIRIT response with respect to the vmr of the gases measured was tested. For $\mathrm{CH}_{4}$ and $\mathrm{CO}$, the test consisted in using five gas cylinders containing calibrated vmr that were alternatively sent to SPIRIT inlet in a pseudorandom sequence. Each gas mixture was sent during $20 \mathrm{~min}$ at least three times during the exercise. The reference values for the five cylinders were obtained by CRDS measurement with a G2401 analyzer (PICARRO) at the ICOS ATC Metrology Lab (located at LSCE/IPSL, Gif-sur-Yvette, France) calibrated against the international primary scales (NOAA-2004 for $\mathrm{CH}_{4}$ and WMO-CO-X2004 for $\mathrm{CO}$ [24]). As illustrated in Figs. 5a and 6a, we found an excellent linear behavior for both species, with squared correlation coefficients $R^{2}$ better than 0.999 and no evidence of a high-order polynomial dependence on the linear fit residuals (Figs. 5b, $6 b)$.

For $\mathrm{CO}$, the main contribution to the difference between measurements and reference gas values for vmr lower than

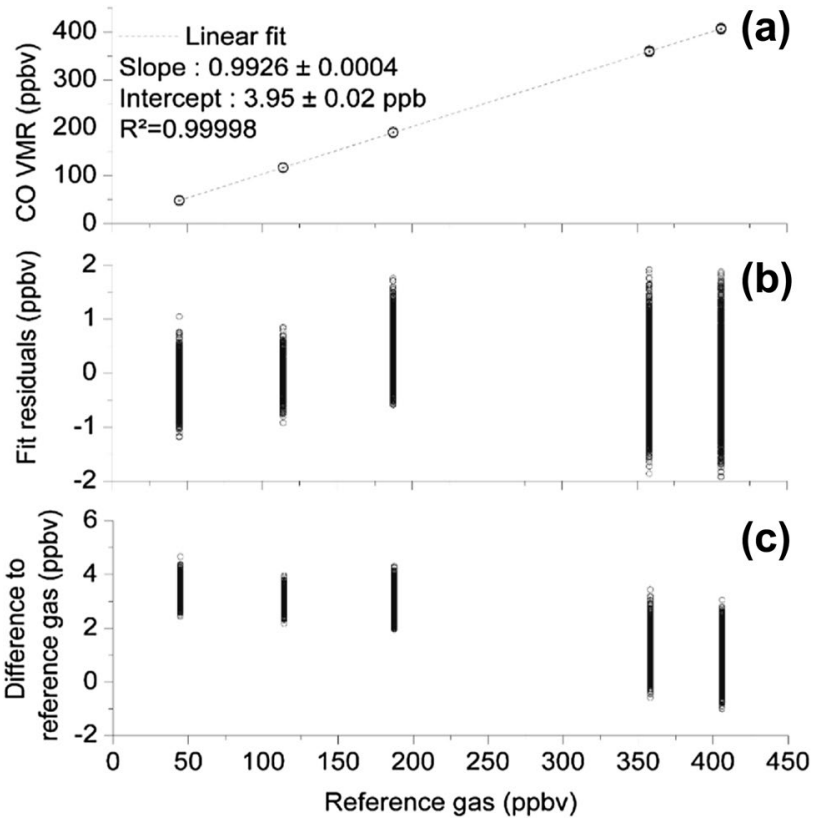

Fig. 5 CO measurements of SPIRIT for five calibration cylinders (at $20.0{ }^{\circ} \mathrm{C}$ and $32.8 \mathrm{hPa}$, with pathlength of $134.22 \mathrm{~m}$ ): a raw measurements with linear fit, $\mathbf{b}$ fit residuals calculated as the difference between the measured value and the linear fit, and $\mathbf{c}$ difference between the measured vmr and the reference vmr as a function of the reference vmr. Reference calibrated values are $44.73 \pm 0.38,113.94 \pm 0.33,187.31 \pm 0.37,358.10 \pm 0.32$, and $405.95 \pm 0.29 \mathrm{ppbv}$

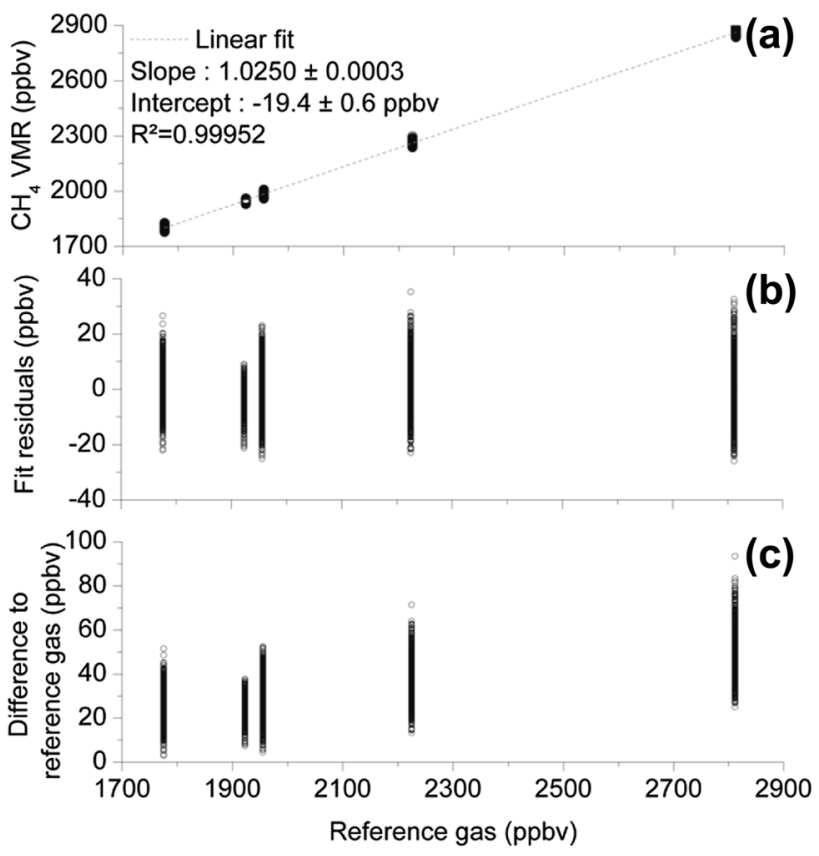

Fig. 6 Same as Fig. 5, but for $\mathrm{CH}_{4}$ measurements. Reference calibrated values are $1775.59 \pm 0.17,1922.83 \pm 0.19,1955.38 \pm 0.23$, $2224.91 \pm 0.24$, and $2811.64 \pm 0.35 \mathrm{ppbv}$

200 ppbv (Fig. 5c) comes from a constant offset of $3.95 \mathrm{ppbv}$ clearly visible on the linear fit parameters (Fig. 5a). To explain the origin of this bias, we analyzed pure nitrogen $(\geq 999,997 \%)$ after it was sent into a CO cold trap (Sofnocat 514). Although the CO residual vmr should have been less than 0.1 ppbv, SPIRIT still detected a clear spectral signature, where the $\mathrm{CO}$ line represented $2.6 \pm 1 \mathrm{ppbv}$ of CO. A second test was performed, which consisted in interrupting the gas flow in the analyzer cell. After several hours, the $\mathrm{CO}$ vmr increased by more than a factor of 5 with respect to the vmr in the ambient air, refuting the possibility that this difference could result from a leak in the optical cell. This rather suggests the presence of a piece of the equipment outgassing $\mathrm{CO}$ (or another gas which exhibits an absorption line, where the $\mathrm{CO}$ line is measured) in the gas circuitry or inside the measurement cell. Unfortunately, despite the efforts made in this direction, we have not been able to identify this source. If this offset (Fig. 5a) is subtracted, the agreement between reference and measured values is very good (>99.2\%). The small difference could result from a constant error on measured pressure, optical path length, or temperature inside the cell, but in all likelihood is due for the most part to the inaccuracy on the spectroscopic parameter given for this line in HITRAN (between 2 and 5\%) [22].

For $\mathrm{CH}_{4}$, one can observe (Fig. 6a) a small constant bias of about $-19.4 \mathrm{ppbv}$ for an extrapolated reference value of 0 ppbv. However, considering the narrow span of calibrated gases used (from 1776 to $2812 \mathrm{ppbv}$ ) and a measurement 
dispersion of more than 40 ppbv peak-to-peak, this value cannot be considered meaningful, but still could result from a small deviation from linearity as we have no evidence of methane trapping in the cell. Once this bias is removed, the average difference is $2.5 \%$, as shown in Fig. 6a, and is again consistent with the inaccuracy on the spectroscopic parameters given in HITRAN (between 2 and 5\% for the line intensity) [22].

Consequently, the fit residuals (Figs. 5b, 6b) show no particular deviation from linear adjustment. At lower concentrations, these residuals cannot be suppressed to attain pure shot noise, since they are due to unavoidable interference fringes between the direct beam of the laser and the light scattered by optical components on the beam path, while at higher concentrations, these residuals mainly originate from inaccuracy in the line fitting, due to limited accuracy of the spectroscopic parameters.

A long-term comparison was made with an Ultraportable Greenhouse Gas Analyzer (UGGA, Los Gatos Research, USA), based on Off-Axis Integrated Cavity Output Spectroscopy (OA-ICOS) [14]. The comparison consisted of sampling outdoor air on the lab roof and regularly (every $2.5 \mathrm{~h}$ during $20 \mathrm{~min}$ ) a target gas from a cylinder (whose $\mathrm{CH}_{4} \mathrm{vmr}$ is fixed). As shown in Fig. 7, the two instruments exhibit a remarkable correlation, with relative differences remaining within $\pm 1 \%$ for more than $33 \mathrm{~h}$ even with ambient $\mathrm{CH}_{4}$ level varying by more than $10 \%$. The vmr sudden decreases to the lower values due to target sampling are repeatable (within $1 \%$ ). A slight instrumental drift only arose after $13 \mathrm{~h}$, which is difficult to be assigned to one of the instruments. The spikes lasting a few seconds, shown in the lower panel, corresponding to more than $1 \%$ difference between both instruments, are due to their different response times during transition regimes between ambient air and target gas samplings.

As $\mathrm{NO}_{2}$ propensity to degrade (especially in the presence of humidity) makes it difficult to obtain highly accurate mixing ratios without specially designed equipment even from calibrated cylinders, linearity had to be estimated differently. SPIRIT and an AC-31M (Environnement SA) were installed in parallel at the output of a dilution stage generating volume mixing ratios in the range $0-6 \mathrm{ppbv}$. The $\mathrm{AC}-31 \mathrm{M}$ is a double-channel chemiluminescence $\mathrm{NO}_{x}$ analyzer and was calibrated just before the test. The correlation between both instruments for $\mathrm{NO}_{2}$ is rather good, given the uncertainties on the measurements of AC-31M ( \pm 0.5 ppbv $)$ and SPIRIT (estimated by the standard deviation on the $\mathrm{NO}_{2}$ fitting retrieval residuals, largely predominant with respect to all other sources of uncertainties in this vmr range), with a coefficient of determination $R^{2}$ of about 0.979 , as shown in Fig. 8. The $\mathrm{NO}_{2}$ vmr measured by SPIRIT is on average about 5\% above the AC-31M value (indicated from the slope).

\subsection{In-flight performances}

An experiment to characterize the in-flight performances of SPIRIT about $\mathrm{CO}$ and $\mathrm{CH}_{4}$ was performed during a flight from the ATR-42, operated by the French Airborne
Fig. 7 Comparisons between SPIRIT (grey color) and the UGGA from Los Gatos Research (blue color) for $\mathrm{CH}_{4}$ measurements in laboratory. Upper panel vmr measurements during more than $33 \mathrm{~h}$ for both instruments; Lower panel relative difference in $\%$ between both instruments
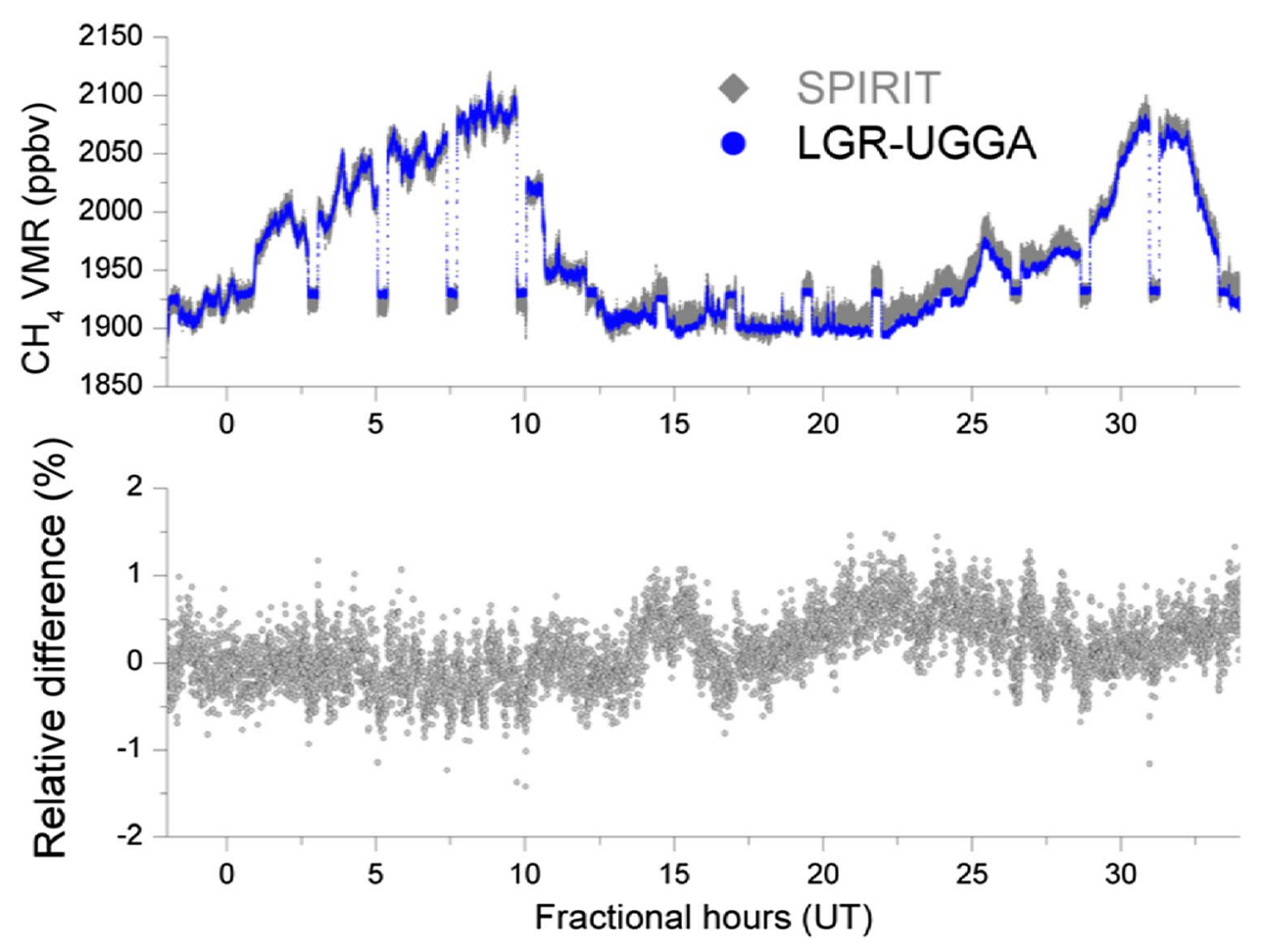


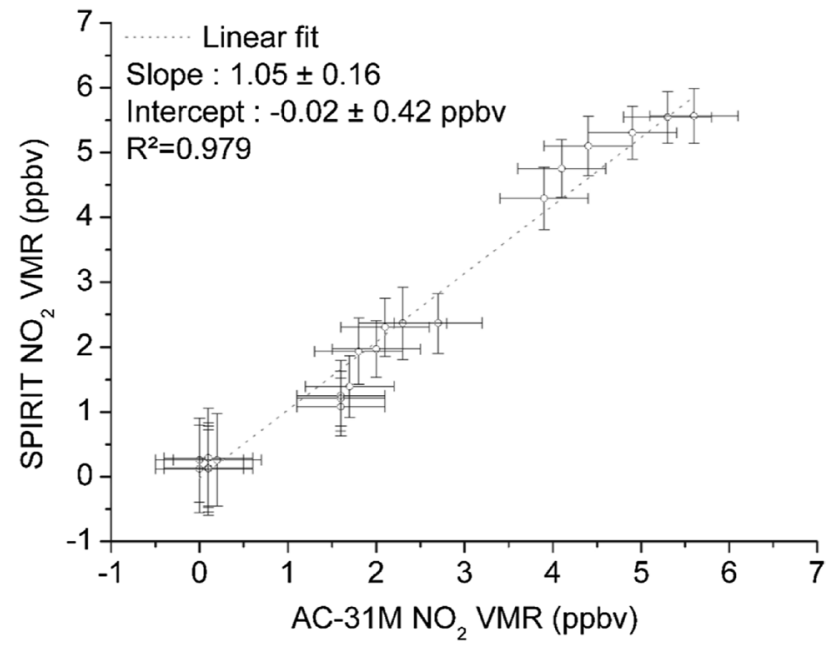

Fig. 8 Laboratory comparison between SPIRIT (at $29.0{ }^{\circ} \mathrm{C}$ and $32.8 \mathrm{hPa}$, with pathlength of $134.22 \mathrm{~m}$ ) and a chemiluminescence $\mathrm{NO}_{x}$ analyzer. Error bars for SPIRIT are estimated by the standard deviation $(1 \sigma)$ on the $\mathrm{NO}_{2}$ fit residuals, the main contribution to the uncertainty budget in this measurement range. The accuracy displayed for the AC-31M (Environnement SA) is the one reported in the instrument datasheets $(0.5 \mathrm{ppbv})$

Environment Research Service (SAFIRE, INSU-Météo France), on February 5, 2016. It consisted in alternating measurements of sampled air and of a gas mixture cylinder of $\mathrm{CO}$ and $\mathrm{CH}_{4}$ calibrated on the international primary scales (from ATC Metrology Lab, LSCE [24]), as illustrated in Fig. 9. The purpose of measuring a reference mixture along the flight was to assess long-term drifts (on the timescale of a flight) under the influences of the cabin temperature and the atmospheric temperature and pressure, in particular during atmospheric changes due to vertical profiling. One can see that there is no significant correlation between the altitude (from ground to $5700 \mathrm{~m}$ above sea level), i.e., the external atmospheric pressure and temperature, and the $\mathrm{CO}$ and $\mathrm{CH}_{4}$ calibrated values measured by SPIRIT.

As expected (Fig. 9b), the $\mathrm{CO}$ vmr measured for the calibrated mixture shows a constant bias along the flight with a mean value of $+3.8 \mathrm{ppbv}$ and a standard deviation of $0.4 \mathrm{ppbv}$ compared to the cylinder value. Considering the 0.4 ppbv accuracy on the cylinder vmr, this bias is in a very good agreement with the measurements performed on calibration cylinders at ground, which should theoretically lead to an overestimation of the mixing ratio for $\mathrm{CO}$ of about $2.9 \pm 0.1 \mathrm{ppbv}$ by SPIRIT for this 136.05 ppbv calibrated vmr (given the expression of the linear fit, as shown in Fig. 5a).

For $\mathrm{CH}_{4}$ (Fig. 9c), the average difference during the measurement with the calibration gas is $+4.7 \mathrm{ppbv}$, with a standard deviation of $7.8 \mathrm{ppbv}$, which is less than the expected value (+29.1 ppbv) deduced from the ground calibration but still consistent; considering the extreme values

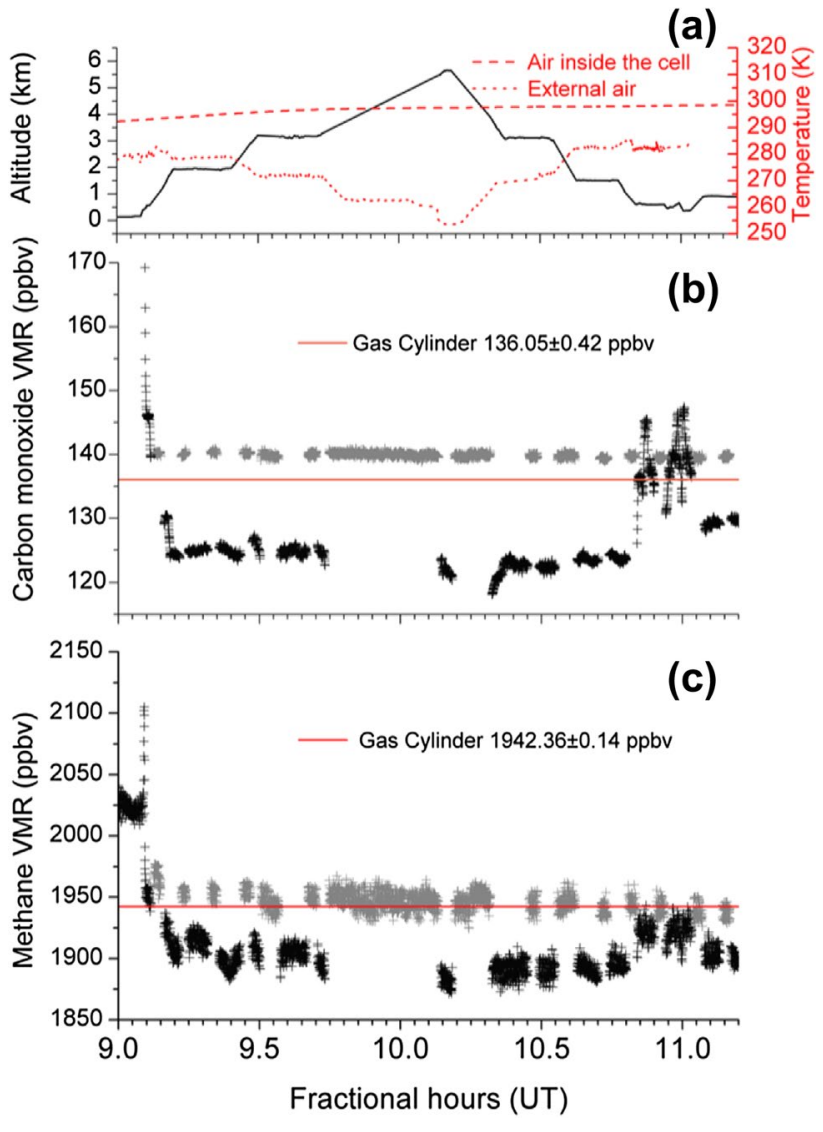

Fig. 9 ATR-42 flight on February 5, 2016. a Altitude and temperature profiles. b $\mathrm{CO}$ measurements. $\mathbf{c} \mathrm{CH}_{4}$ measurements. For $\mathbf{b}$ and $\mathbf{c}$, the grey crosses represent the moments when the calibrated gas cylinder content was measured and the black crosses the moments when the external air was measured. The transients during the passage from the gas cylinder to the external sampling have been removed from the plot to improve its readability

from measurement of the calibration gas can differ by about 20 ppbv with respect to the reference calibrated gas, as shown in Fig. 6c.

One can also observe in Fig. 9 that the measured vmr for the gas cylinder vary along the flight duration. For $\mathrm{CO}$ and $\mathrm{CH}_{4}$, the relative maximum variations represent 0.7 and $1.46 \%$, respectively. This "long-term" drift shows neither direct correlation with the temperature (within these \%) nor with the pressure inside the cell, but results from the fringe pattern changing with the mechanical variation of the optical bench with temperature. This pattern can basically be seen as a sum of sinusoids which modulates the spectrum and whose frequencies are integer multiples of $c / 2 L_{\mathrm{i}}$, with c being the speed of light and $L_{\mathrm{i}}$ the optical distance between two parallel optical diopters in the beam path. Unfortunately, the large number of diopters makes this pattern and its evolution eminently non-deterministic, so it is not possible to subtract it from the signal. Nevertheless, as it is inherently 
limited in amplitude and rate, this drift is hardly detrimental to measurement, since SPIRIT is designed primarily to characterize geophysical phenomena limited in time (a few minutes) and space (a few $\mathrm{km}$ ), which are clearly distinguishable from background residual vmr.

Another characteristic of the instrument is the $1 \sigma$ precision or sensitivity, i.e., the lowest vmr variation the instrument is able to reliably detect over a noisy background. Following a current practice in atmospheric trace-gas measurements [7, 24], sensitivities for $\mathrm{CO}$ and $\mathrm{CH}_{4}$ are deduced from the Allan deviation (a measure of the precision as a function of averaging time [25]), calculated here for the flight between 9:45 and 10:08 (UT). As illustrated in Fig. 10, these precisions for $\mathrm{CO}$ and $\mathrm{CH}_{4}$ are about 0.3 and $5 \mathrm{ppbv}$ at $1.6 \mathrm{~s}$, and 0.2 and $3 \mathrm{ppbv}$ at $9 \mathrm{~s}$ averaging (the maximum response time of SPIRIT), respectively. Considering averaging times longer than a few minutes makes no sense in the context in which the instrument is used.

For $\mathrm{NO}_{2}$ in-flight measurement evaluation, a direct comparison has been made with two $\mathrm{NO}_{x}$ chemiluminescent analyzers operated by SAFIRE in the ATR- 42 aircraft: the Model 42C and 42S from Thermo Environmental Instruments (TEI). Usually, $\mathrm{NO}_{2}$ levels in the free troposphere above the French countryside are relatively low, below the detection limit of SPIRIT ( 0.3 ppbv; see below). During a flight (on May 27, 2014), the plane executed seven quick loops, which allowed to make measurements inside its own exhaust trails, where $\mathrm{NO}_{2}$ levels are several times higher than the background level. Results presented in Fig. 11 show the agreement between SPIRIT and both instruments on average within about $0.5 \mathrm{ppbv}$. Moreover, this value is consistent with the accuracy indicated by the TEI Company for these two models and with the results of the laboratory

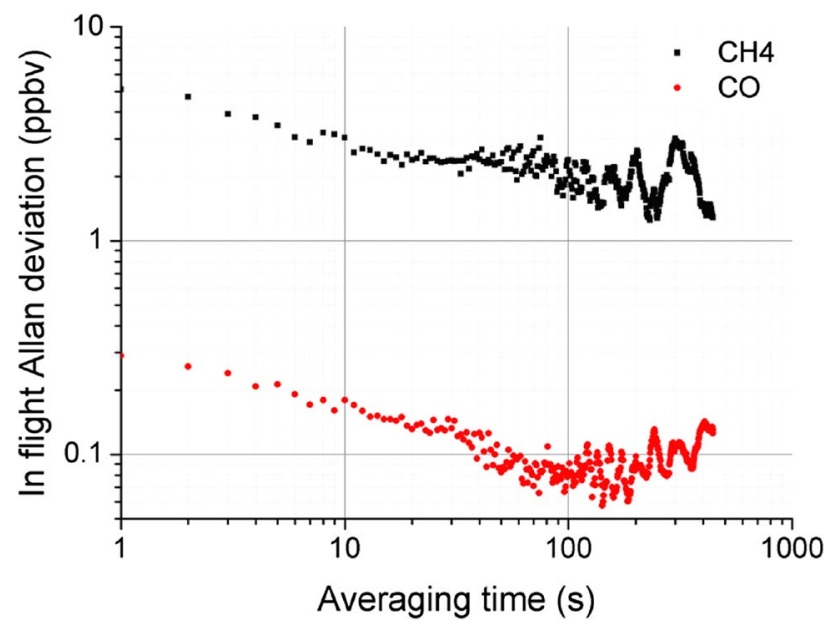

Fig. 10 In-flight Allan deviation for $\mathrm{CO}$ and $\mathrm{CH}_{4}$. The minima are clearly visible at about $0.06 \mathrm{ppbv}$ for $\mathrm{CO}$ (150 s averaging) and $1.5 \mathrm{ppbv}$ for $\mathrm{CH}_{4}$ (for $150 \mathrm{~s}$ )
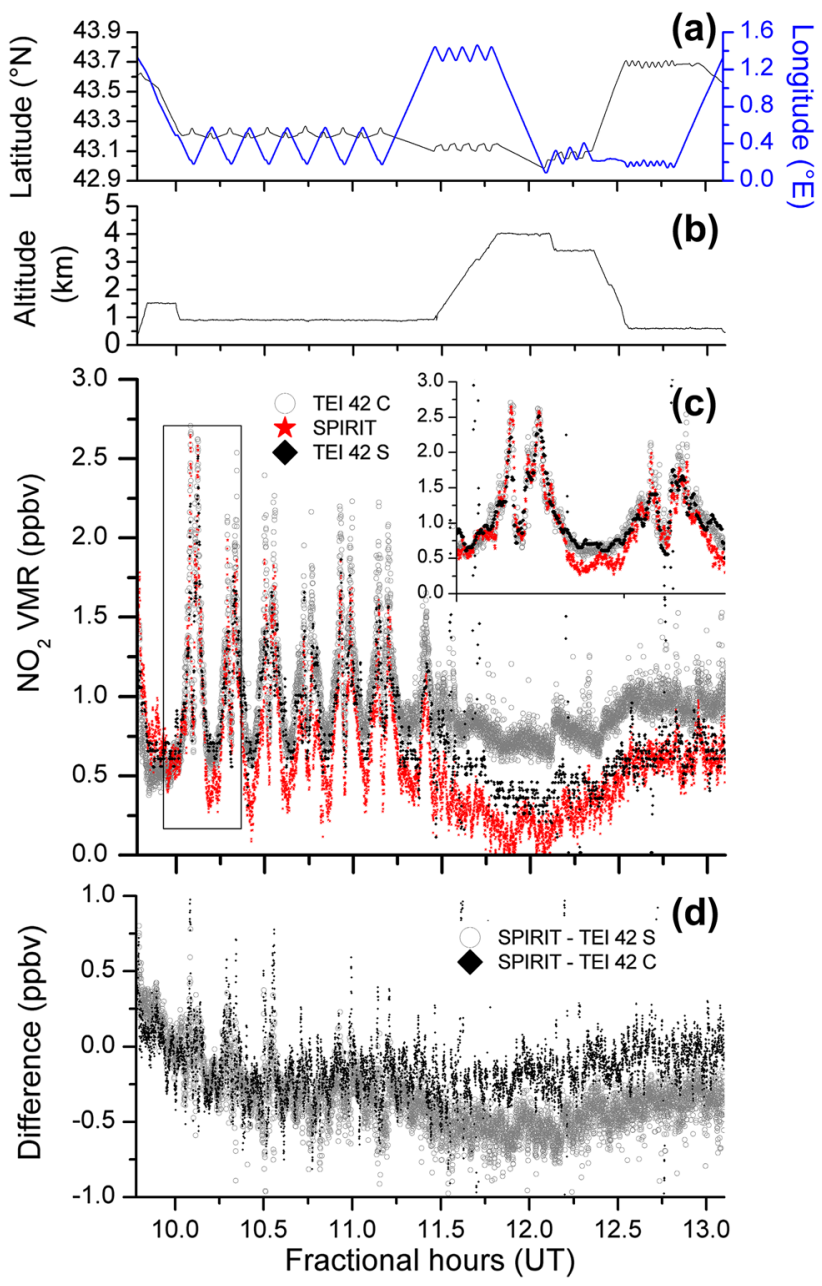

Fig. 11 ATR-42 flight on May 27, 2014. Upper panel Latitude, longitude, and altitude profiles showing the six loops completed by the plane between 10 and $11.25 \mathrm{am}$. Insert zoom of the framed data around 10 UT. Middle panel Comparison of $\mathrm{NO}_{2}$ measurements by SPIRIT and TEI models $42 \mathrm{C}$ and $42 \mathrm{~S}$. $\mathrm{NO}_{2}$ increases result from the plane flying inside its exhaust wake. Lower panel difference in ppbv between SPIRIT and TEI models

experiments when comparing SPIRIT to another commercial instrument (AC-31M, Fig. 8), giving thus an estimate of the in-flight accuracy for $\mathrm{NO}_{2}$. The instantaneous (1.6 s) $1 \sigma$ precision of about 0.3 ppbv can also be roughly derived from the SPIRIT data scatter, as shown in Fig. $11 \mathrm{c}$, without taking into account the lower frequency variations, and can be assimilated to the detection limit.

Essential performances concerning the uncertainties of the measurements by SPIRIT are summarized in Table 2. The $1 \sigma$ precisions at $1.6 \mathrm{~s}$ are remembered for each species. The overall uncertainties can be estimated from inflight measurements. Comparisons with calibrated cylinder gases tied to WMO standard for CO, to NOAA standard for $\mathrm{CH}_{4}$, and with measurements from two different instruments for $\mathrm{NO}_{2}$ (models $42 \mathrm{C}$ and $42 \mathrm{~S}$ from TEI), led to biases and 
Table 2 Precisions and overall uncertainties of in-flight measurements for $\mathrm{CO}, \mathrm{CH}_{4}$, and $\mathrm{NO}_{2} \mathrm{vmr}$

\begin{tabular}{lll}
\hline Molecule & $1 \sigma$ precision at $1.6 \mathrm{~s}$ & $\begin{array}{l}\text { Overall uncertainties with (or } \\
\text { without) calibration }\end{array}$ \\
\hline $\mathrm{CO}$ & $0.3 \mathrm{ppbv}$ & 0.9 (or 4.7$) \mathrm{ppbv}$ at $150 \mathrm{ppbv} \mathrm{CO}$ \\
$\mathrm{CH}_{4}$ & $5 \mathrm{ppbv}$ & 22 (or 27$) \mathrm{ppbv}$ at $1900 \mathrm{ppbv} \mathrm{CH}_{4}$ \\
$\mathrm{NO}_{2}$ & $0.3 \mathrm{ppbv}$ & $0.5 \mathrm{ppbv}(+5 \%)$ \\
\hline
\end{tabular}

associated standard deviations of $3.8 \pm 0.4=4.2 \mathrm{ppbv}$ for $\mathrm{CO}, 4.7 \pm 7.8=12.5$ ppbv for $\mathrm{CH}_{4}$, and 0.5 ppbv for $\mathrm{NO}_{2}$, taking into account the experimental scatters. The longterm drifts of $0.7 \%$ for $\mathrm{CO}$ and $1.5 \%$ for $\mathrm{CH}_{4}$ (Fig. 9) lead to \pm 0.5 and \pm 14 ppbv uncertainties at typical atmospheric vmr values of 150 and $1900 \mathrm{ppbv}$, respectively, whereas the comparison for $\mathrm{NO}_{2}$ with AC-31M instrument (from Environnement SA) in laboratory leads to $5 \%$ overestimation of SPIRIT values (Fig. 8). Directly adding these uncertainties with taking into account (or not) calibration leads to estimated overall uncertainties on vmr of 0.9 (or 4.7) ppbv for $\mathrm{CO}, 22$ (or 27) ppbv for $\mathrm{CH}_{4}$, and $0.5 \mathrm{ppbv}(+5 \%)$ for $\mathrm{NO}_{2}$.

\section{Conclusions and perspectives}

We presented the newly built instrument SPIRIT, a compact infrared absorption spectrometer with three quantum cascade lasers operating automatically on aircraft to measure at least three trace gases, for instance, $\mathrm{CO}, \mathrm{NO}_{2}$, and $\mathrm{CH}_{4}$ in the present study. SPIRIT has already been applied with success in several large field campaigns, such as those linked to FP7 European projects SHIVA [26, 27] and DACCIWA-EUFAR-APSOWA [28, 29] and to national projects such as MISTRAL-CHARMEX [30]. Enhanced volume mixing ratios of $\mathrm{CO}, \mathrm{NO}_{2}$, and/or $\mathrm{CH}_{4}$ of a few ppbv to tens of ppbv were observed during flights when crossing, in the upper troposphere convective clouds rapidly transporting near-surface polluted air, in the boundary layer pollutant emission plumes from offshore oil extraction platforms, and in the middle troposphere air masses containing biomass burning products transported over a long distance.

The main advantages of SPIRIT lie in its robustness and versatility, both arising from the use of a broadband multipass cell. It allows the laser to be changed easily to target species according to the scientific objectives. Thereby, other species such as $\mathrm{CO}_{2}$, ozone $\left(\mathrm{O}_{3}\right)$, carbonyl sulfide (OCS), formaldehyde $(\mathrm{HCHO})$, and hydrogen peroxide $\left(\mathrm{H}_{2} \mathrm{O}_{2}\right)$ may be detected with performances that remain to be determined.

Several improvements can be foreseen. To address the problem of measuring gases particularly sticky or reactive, it appears necessary to improve the gas supply system. One improvement that could be easily achieved consists in reducing the residence time inside the cell and the gas lines.
With the present pump capacities, it is possible to achieve gas flows more than five times as high just by replacing the orifice of the pressure regulator valve with a larger one. The residence time of the gas inside the instrument should thus be reduced by the same order of magnitude, without necessarily reducing the quality of the pressure regulation. Another aspect is to improve the compatibility of the wetted materials with gases, some surface treatments such as amorphous silicon coatings which seem to be able to ensure a relative chemical inertness and to drastically reduce adsorption. Heating the gas lines should also be considered as adsorption is highly dependent on the temperature of the walls.

A further improvement also includes regulating the temperature of the optical bench or at least the measurement cell. Although it would not result in an improvement of detection limit, because the short-term precision is mainly limited by relative changes in the optical path length of the order of the wavelength, resulting from vibrations from the pump and the plane, it should drastically enhance long-term accuracy and hence provide the opportunity to study phenomena having low spatial and temporal variability. This temperature regulation should stabilize the fringe pattern, and thus reduce the standard deviation of the average mixing ratios when combined to regular in-flight calibrations using reference cylinders. This should lower the minimum of the Allan deviation such as experienced in ground measurements by our team, reaching precisions below $0.3 \%$ [31]. The accuracy of the measured values depends on the calibration strategy deployed and the field constraints. When it is not possible to embark calibration gas cylinders, such as in the cases exemplified above, checking the absence of significant drift (i.e., within orders of magnitude of the biases plus the associated standard deviations) of known target gases before and after each flight is enough, since it does not compromise the findings of the pollution event studies. Sometimes also, the aircraft flies over calibrated measurement surface stations from the World Meteorological Organization/Global Atmosphere Watch/ICOS networks, which, taking into account the wind trajectories, allows validations of the measurements.

Finally, the opportunity to use Interband Cascade Lasers (ICLs) in the future should be considered for species having their fundamental vibrational transition lying in the 3-6$\mu \mathrm{m}$ region. This type of laser offers interesting capabilities compared to QCLs: a higher operating temperature, a larger current tunability, and a better optical efficiency allowing for operation at lower electrical power (at the expense of a lower optical output power that could be limiting for the use of multipass cells). However, for the time being, this technology is still less mature than that of the QCLs, and being mastered by a single manufacturer makes ICLs less affordable than QCLs. 
Acknowledgements The authors gratefully acknowledge Gilles Chalumeau, Stéphane Chevrier, Luc Pomathiod, and Kevin Le Letty for engineering and construction of the SPIRIT instrument and for operations during the campaigns and Olivier Laurent (ICOS ATC Metrology Lab, LSCE) for the supply and calibration of the $\mathrm{CO}$ and $\mathrm{CH}_{4}$ gas mixtures. This work has been made possible thanks to the fruitful collaboration with the SAFIRE team (INSU-Météo France) and to the support of the ChemCalInt group: A. Borbon (LaMP/CNRS) in charge of the coordination, and S. Sauvage and E. Tison (IMT Lille/SAGE) in charge of the intercomparison facility and experiments. ChemCalInt is a French initiative part of the European JRA TGOE in EUFAR for the traceability in gas-phase observations' on-board research aircraft.

This work was funded by the European project SHIVA (FP7-ENV-2007-1-226224), the Labex VOLTAIRE (ANR-10LABX-100-01), and the PIVOTS project provided by the Région Centre-Val de Loire (ARD 2020 program and CPER 2015-2020).

\section{Compliance with ethical standards}

Conflict of interest The authors declare that they have no conflict of interest.

Open Access This article is distributed under the terms of the Creative Commons Attribution 4.0 International License (http://creativecommons.org/licenses/by/4.0/), which permits unrestricted use, distribution, and reproduction in any medium, provided you give appropriate credit to the original author(s) and the source, provide a link to the Creative Commons license, and indicate if changes were made.

\section{References}

1. A. Fried, G. Diskin, P. Weibring, D. Richter, J.G. Walega, G. Sachse, T. Slate, M. Rana, J. Podolske, Appl. Phys. B 92, 409 (2008)

2. J. McQuaid, H. Schlager, M.D. Andrés-Hernández, S. Ball, A. Borbon, S.S. Brown, V. Catoire, P. Di Carlo, T.G. Custer, M. von Hobe et al., In situ trace gas measurements, in airborne measurements, in Methods and instruments, ed. by M. Wendisch, J.L. Brenguier (Wiley, Weinheim, 2013)

3. K. Krzempek, M. Jahjah, R. Lewicki, P. Stefański, S. So, D. Thomazy, F.K. Tittel, Appl. Phys. B 112, 461 (2013)

4. A.W. Rollins, T.D. Thornberry, R.S. Gao, J.B. Smith, D.S. Sayres, M.R. Sargent, C. Schiller, M. Krämer, N. Spelten, D.F. Hurst et al., J. Geophys. Res. Atmos. 119, 1915 (2014)

5. C. Dyroff, S. Sanati, E. Christner, A. Zahn, M. Balzer, H. Bouquet, J.B. McManus, Y. González-Ramos, M. Schneider, Atmos. Meas. Tech. 8, 2037 (2015)

6. M.L. Smith, E.A. Kort, A. Karion, C. Sweeney, S.C. Herndon, T.I. Yacovitch, Environ. Sci. Technol. 49, 8158 (2015)

7. G.W. Santoni, B.C. Daube, E.A. Kort, R. Jiménez, S. Park, J.V. Pittman, E. Gottlieb, B. Xiang, M.S. Zahniser, D.D. Nelson et al., Atmos. Meas. Tech. 7, 1509 (2014)

8. J.R. Pitt, M. Le Breton, G. Allen, C.J. Percival, M.W. Gallagher, S.J.-B. Bauguitte, S.J. O'Shea, J.B.A. Muller, M.S. Zahniser, J. Pyle, P.I. Palmer, Atmos. Meas. Tech. 9, 63 (2016)

9. D. Richter, P. Weibring, J.G. Walega, A. Fried, S.M. Spuler, M.S. Taubman, Appl. Phys. B 119, 119 (2015)

10. C.W. Rella, H. Chen, A.E. Andrews, A. Filges, C. Gerbig, J. Hatakka, A. Karion, N.L. Miles, S.J. Richardson, M. Steinbacher, C. Sweeney, B. Wastine, C. Zellweger, Atmos. Meas. Tech. 6, 837 (2013)
11. J. Beecken, J. Mellqvist, K. Salo, J. Ekholm, J.-P. Jalkanen, Atmos. Meas. Tech. 7, 1957 (2014)

12. A. Karion, C. Sweeney, E.A. Kort, P.B. Shepson, A. Brewer, M. Cambaliza, S.C. Conley, K. Davis, A. Deng, M. Hardesty, Environ. Sci. Technol. 49, 8124 (2015)

13. E.S.F. Berman, M. Fladeland, J. Liem, R. Kolyer, M. Gupta, Sens. Actuators B Chem. 169, 128 (2012)

14. S.J. O'Shea, S.J.-B. Bauguitte, M.W. Gallagher, D. Lowry, C.J. Percival, Atmos. Meas. Tech. 6, 1095 (2013)

15. C. Dyroff, A. Zahn, S. Sanati, E. Christner, A. Rauthe-Schöch, T.J. Schuck, Atmos. Meas. Tech. 7, 743 (2014)

16. I. Ventrillard, I. Xueref-Remy, M. Schmidt, C. Yver Kwok, X. Faïn, D. Romanini, Atmos. Meas. Tech. Discuss (2016). doi:10.5194/amt-2016-386

17. J.B. McManus, D.D. Nelson, S. Herndon, J.H. Shorter, M. Zahniser, S. Blaser, L. Hvozdara, A. Muller, M. Giovannini, J. Faist, Appl. Phys. B 85, 235 (2006)

18. Moreau G, Robert C, Rigaud P (1989) In: Proc. Quad. Ozone Symp. Göttingen FRG, 4-13 August 1988. Bojkov RD, Fabian P (Eds). D. Reidel, Dordrecht, p 755

19. Moreau G, Camy-Peyret C, Robert C et al (1997) In: Proceedings of the 13th ESA Symposium on European Rocket and Balloon Programmes and Related Research. ESA, Öland, SP-397, 421

20. G. Moreau, C. Robert, V. Catoire, M. Chartier, C. Camy-Peyret, N. Huret, M. Pirre, L. Pomathiod, G. Chalumeau, Appl. Opt. 44, $5972(2005)$

21. C. Robert, Appl. Opt. 46, 5408 (2007)

22. L.S. Rothman, I.E. Gordon, Y. Babikov, A. Barbe, D. Chris Benner, P.F. Bernath, M. Birk, L. Bizzocchi, V. Boudon, L.R. Brown et al., J. Quant. Spectrosc. Radiat. Transf. 130, 4 (2013)

23. C. Guimbaud, V. Catoire, S. Gogo, C. Robert, F. LaggounDéfarge, M. Chartier, A. Grossel, P. Albéric, L. Pomathiod, B. Nicoullaud, G. Richard, Meas. Sci. Technol. 22, 075601 (2011)

24. C. Yver Kwok, O. Laurent, A. Guemri, C. Philippon, B. Wastine, C.W. Rella, C. Vuillemin, F. Truong, M. Delmotte, V. Kazan, M. Darding, B. Lebègue, C. Kaiser, I. Xueref-Rémy, M. Ramonet, Atmos. Meas. Tech. 8, 3867 (2015)

25. P. Werle, R. Mucke, F. Slemr, Appl. Phys. B 57, 131 (1993)

26. K. Grossman, M. Dorf, M. Kenntner, V. Catoire, H. Schlager, F. Hendrick, I. DeSmedt, Y. Huan, K. Pfeilsticker, Malays. J. Sci. 32, 259 (2013). (SCS Sp Issue)

27. G. Krysztofiak, V. Catoire, C. Robert, P. D. Hamer, V. Marécal, A. Engel, H. Bönisch, K. Grossman, K. Pfeilsticker (2017) Atmos. Sci. Lett. (in revision)

28. Catoire V, Krysztofiak-Tong G. http://www.eufar.net/ weblog/2016/12/12/air-pollution-shipping-and-oilgas-platformsemissions-observed-during-airborne-eufar-apsowa-campaign/

29. C. Flamant, P. Knippertz, A. Akpo, B. Brooks, C. Chiu, H. Coe, S. Danuor, M. Evans, A. Fink, O. Jegede, N. Kalthoff, A. Konaré, C. Liousse, F. Lohou, C. Mari, H. Schlager, A. Schwarzenboeck, B. Adler, L. Amekudzi, J. Aeyee, M. Ayoola, A. Batenburg, G. Bessardon, S. Borrmann, J. Brito, K. Bower, F. Burnet, V. Catoire et al., (2017) Bull. Am. Meteorol. Soc. doi:10.1175/ BAMS-D-16-0256.1

30. P. Ricaud, R. Zbinden, V. Catoire, V. Brocchi, F. Dulac, E. Hamonou, J.-C. Canonici, L. El Amraoui, S. Massart, B. Piguet, U. Dayan et al., (2017) Bull. Am. Meteorol. Soc. doi:10.1175/ BAMS-D-16-0226.1

31. C. Guimbaud, C. Noel, M. Chartier, V. Catoire, M. Blessing, J.C. Gourry, C. Robert (2016) J. Environ. Sci. http://dx.doi. org/10.1016/j.jes.2015.11.015 